\title{
The Effects and Antecedents of Perceived Fairness in the Deliberative Process for Sustainable Citizens' Participation
}

\author{
Jungin Kim
}

Citation: Kim, J. The Effects and Antecedents of Perceived Fairness in the Deliberative Process for Sustainable Citizens' Participation. Sustainability 2021, 13, 7735.

https://doi.org/10.3390/su13147735

Academic Editor: Ermanno C. Tortia

Received: 6 June 2021

Accepted: 8 July 2021

Published: 11 July 2021

Publisher's Note: MDPI stays neutral with regard to jurisdictional claims in published maps and institutional affiliations.

Copyright: (C) 2021 by the author. Licensee MDPI, Basel, Switzerland. This article is an open access article distributed under the terms and conditions of the Creative Commons Attribution (CC BY) license (https:/ / creativecommons.org/licenses/by/ $4.0 /)$.
Department of Public Administration, The University of Suwon, 17, Wauan-gil, Bongdam-eup, Hwaseong 445743, Korea; jungink@suwon.ac.kr

\begin{abstract}
Based on the data from Korean citizen's deliberation experiments, we examined the effects and antecedents of perceived fairness of the deliberative process. Our empirical study tested whether the perceived fairness of the deliberative process was associated with the outcomes of deliberation (changes in civic participants' opinions) and explored antecedents that facilitated the perceived fairness of the deliberative process. We found that perceived fairness of the deliberative process positively increased civic participants' opinion change, information reliability, and culture of acceptance in the deliberative process cultivated the perceived fairness of deliberative process when we controlled personal orientation and characteristics (e.g., political orientation, gender, age and etc.). These results identified conditions for effectively facilitating deliberative civic engagement in the policy decision-making process.
\end{abstract}

Keywords: culture of acceptance; deliberative democracy; information reliability; perceived fairness

\section{Introduction}

Citizens' participation based on deliberative democracy has become increasingly important in the policy process [1]. In fact, deliberation has become "the most active area of political theory in its entirety" [2] (p. 237), and can improve citizens' political competence by facilitating their arguments and opinions [3]. That is, deliberative democracy emphasizes citizens' comprehensive participation in political decision-making [4]. Although the deliberative process can be vague [5], deliberative democracy has been emphasized as an alternative to representative democracy [6,7].

Deliberative democracy, which is regarded as an exclusively Western form of democracy, comes from the polis of ancient Athens [8]. However, deliberative democracy could be a new solution for policy problems in societies that have little confidence or trust in the democratic process [9]. Recently, deliberative democracy has received attention in some non-Western countries that have maintained an authoritarian policy process for a long time. South Korea, which maintained an authoritarian political system until the late 1980s, is an example of one such country. In the 1970s and 1980s, Korean politicians and bureaucrats engaged in decision-making without considering citizens' opinions. However, since the country's democratization in 1987, civic engagement through democratic discussion has become a major solution to public problems in South Korea. Nevertheless, it is not easy to realize successful civic engagement in the policy decision-making process, where deliberative democracy has not been part of the policy process for a long time.

Thus, we aimed to examine what influences the outcomes of deliberation by focusing on the case of public deliberation regarding the resumption of construction of the Shin-Gori Nuclear Reactors No. 5 and 6 in South Korea in 2017. In particular, the nuclear power plant issue has been decided on solely by the government, without the active participation of citizens in South Korea, which shows an absence of democratic deliberation. As the issue of a nuclear power plant is closely related to the lives of the people, however, we need to examine the extent to which citizens can actively participate in decision-making related to the construction of the nuclear power plant. 
Furthermore, we need to examine how we can improve the outcomes of deliberation. Although numerous empirical studies have been conducted on the outcomes of deliberation, the processes of deliberation, and the effects of deliberative discussions [10-15], few studies have addressed the perceived procedural fairness in the process of deliberative democracy. Thus, we focused on the effects and antecedents of perceived fairness in the deliberative democratic process. More specifically, we examined whether the perceived fairness of the deliberative process increases the outcome of deliberation (i.e., a change in the deliberative participants' opinions) and whether information reliability and acceptance in the deliberative process are antecedent variables that cultivate perceived fairness of the deliberative process. Beyond the case of South Korea, these results could highlight the importance of the successful attainment of deliberative democracy in countries where citizen participation in policy-making processes has been insufficient.

\section{Conceptual Framework}

\subsection{The Effects of Perceived Fairness in the Deliberative Process on Changes in Opinion}

A subject of much debate in the literature is whether deliberation aims to reach consensus among diverse opinions [6,12,16]. Gutmann and Thompson [7] indicated that deliberation could lead to agreements on matters that have not been settled. However, attaining consensus would not always be desirable. For instance, submissive consensus could lead to problems with groupthink, as Janis [17] has suggested. Although debating the validity of the argument that the deliberative process leads to consensus, there has been some agreement on the idea that deliberation based on learning positively affects public policy opinions and preference $[12,18,19]$. That is to say, deliberation could mitigate conflicts between people with different views because it enables deliberative participants to understand one another's views and incorporate various perspectives [20]. Thus, democratic deliberation can be described as a cooperative search for mutual understanding by resolving disagreements between diverse participants [12]. Furthermore, the democratic deliberation process differs from ordinary discussion in that, after the democratic deliberation process, deliberative participants are willing to accommodate different perspectives and change their opinions [12].

Most of all, the effect of deliberation can be achieved when the deliberative process has been fair. Fairness in decision-making refers to the fair procedure of majority rule, which produces legitimate democratic decisions. In the same vein, the fairness of the deliberative process suggests that "citizens ought to have an equal or at least a fair chance to enter their arguments and reasons into the discussion before voting" [21] (pp. 176-177). Fairness in decision-making can be achieved when all participants in the deliberative process are provided with accurate information, equal opportunities to speak, or ample opportunities to appeal, and they are treated impartially and fairly in the process of public debate. Moreover, participants' arguments or convictions must remain impartial, and the views of other participants must be accommodated and respected during collective deliberation [21]. Democratic deliberation entails a collective process of reasoning to achieve an acceptable outcome [22]. Accordingly, civic participants who recognize they are fairly treated in the process of public deliberation are likely to believe that policymakers respect and value their opinions [23].

Numerous empirical studies have indicated that civic participants tend to change their opinions [1]. However, deliberation does not always accompany participants' changes of opinion. For example, an empirical study on the Granada 500 deliberative poll in Britain indicated that participants did not change their opinions after deliberation [24]. The degree to which opinions change depends on the degree of fairness of the deliberative process [25]. In particular, deliberative outcomes are not achieved when groups feel coerced or intimidated in the deliberative process [26]. When participants' overt coercion is not allowed in the deliberative process, participants might change their opinion after the deliberation. 
A deliberative effect occurs when participants are more likely to listen to opinions that are different to their own, and when various opinions are sufficiently accepted [12,23]. Changes in opinion based on many different arguments that lead to an increase in knowledge and more refined opinions $[1,26]$. Such a democratic and fair deliberative process enables participants to change their opinions when they conclude that their opinions are not correct after the process of deliberation $[12,15]$.

Most of all, the participants' change in opinion following deliberation would depend on the extent to which they perceived fairness in the process of deliberative democracy $[15,27]$. When a fair deliberative process is formed, the opinions of people who disagree with others are sufficiently accommodated and accepted based on the principles of reciprocity, publicity, and accountability, increasing the likelihood of achieving a successful outcome $[7,21,23]$. Fair deliberation procedures also encourage individuals to make rational decisions [21].

In this regard, the perceived fairness of the deliberative process tends to lead to changes in opinion. Empirical studies on deliberative democracy have indicated the positive effect of fair procedures of deliberation on participants. For example, a deliberative forum titled Americans Discuss Social Security in Mesa 1998 showed that participants changed their opinions when they kept an open mind, gained new information, and listened to diverse perspectives [12]. Similarly, data from Finland on nuclear power use indicated that opinion on nuclear power issues has changed due to deliberative reasoning and awareness of the issues at stake [25].

Furthermore, from social-psychological studies on interpersonal influence in group settings [28], we can infer that perceived fairness of the deliberative process positively affects changes in policy opinions. Based on contact theory, which states that group contact can reduce prejudice [29], more frequent and fair interaction among group members could reduce their bias and enhance intergroup cooperation [30,31]. In particular, changes of opinion would be pro-social behavior, as they tend to be the result of one's interest in other voices and views [32]. According to contact theory, when public debate is fair, participants in a discussion are more likely to accept others' opinions and change their opinions without prejudice.

Similarly, in the relationship between a fair deliberative process and policy opinion change after deliberation, those who believe the political process is fair are likely to accept the result of the process [33]. When participants perceive the deliberative process to be fair, they are willing to accept the outcome of deliberation. Perceived procedural fairness in deliberation is a critical factor that influences the outcome of deliberation. Thus, the greater the perceived fairness of a public debate's deliberative process, the greater the likelihood of a change in policy opinion after deliberation [15].

Hypothesis 1. Those who perceive the deliberative process to be fair will positively change their policy opinions after the deliberative process.

\subsection{The Antecedents of Perceived Fairness in the Process of Deliberative Democracy}

According to political theory, democratic legitimacy in the decision-making process occurs when perceived procedural fairness is secured in the collective decision-making process [34]. As such, how can perceived procedural fairness in the deliberative process be attained? Since the level of perceived fairness of the deliberative process could depend on the quality of the deliberation associated with adequate information and relevant reasons [35], the level of fairness in the deliberative process can be cultivated using two methods: the level of information reliability and a culture of acceptance.

People tend to want procedures that lead to their decisions to be fair. As a consequence, the psychology of procedural fairness stresses that providing reliable information in decision-making can enhance procedural fairness [36]. When reliable information is provided during decision-making, procedural fairness can be achieved because people can express their opinions through their voices before decisions are made. According to the 
terms 'process control effect' and 'voice effect' [36,37], people tend to evaluate decisionmaking procedures as fair when they are provided with an opportunity to express their views before the decision is made. Furthermore, people believe that the procedural fairness of decision-making can be secured when reliable information relevant to decision-making is provided to them [37]. Thus, the reliability of the information in decision-making can be an antecedent to the fairness of the decision-making procedure. This can be applied in the process of public deliberation.

The reliability of information provided to deliberative participants could be positively associated with the level of fairness in public deliberation. When new information is clearly presented to deliberative participants, they tend to trust such information and eventually perceive the deliberation process to be fair [12,38]. That is, clear and precise information would be better for activating fair deliberation. Moreover, when participants are given enough relevant and precise information to consider alternative scenarios, they have more opportunities to participate in the deliberative process [39]. In this case, deliberative participants are likely to perceive the deliberative process to be fair.

Meanwhile, if the materials that are given to participants in public deliberation lack accuracy and reliability, the participants would not believe that the deliberative process is fair. Deliberative theories have demonstrated that the quality of deliberation depends on the quality of information acquired through learning materials and other sources [10,12].

Hypothesis 2. The reliability of information provided to deliberative participants is positively associated with the procedural fairness they perceive in the deliberative process.

Another important factor in the formation of fairness is the participants' cultural awareness of others in the deliberative process. In general, as culture is formed based on values, common understanding, and behaviors among people, it can provide guidance to their behaviors and perceptions [40]. Cultural scholars have been interested in the effect of cultural differences on people's cognition and behaviors by studying how different cultures change people's values and beliefs [40]. In particular, cultural types can have an effect on the perceptions of procedural fairness in the decision-making process. For example, collectivism, in contrast to individualism, enhances procedural fairness because collectivism prefers to allocate rewards more equally [41]. Furthermore, a culture that fosters the connectedness of people to each other stresses the importance of social exchange in which people's attitudes and behaviors are significantly determined by the levels of their relationships with others [42]. Thus, procedural fairness in the decision-making process depends on the cultural characteristics of relationships with others because the perceived fairness of the decision-making process is socially constructed.

As such, the perception of procedural fairness can be affected by cultural differences. Intolerance of cultural differences suppresses the expression of various opinions in the process of public debate [43]. In group deliberation in a divided society, participants opinions are likely to become extreme and polarized [2]. Meanwhile, a culture willing to include diverse voices could permit civic participants to listen to others' opinions that differ from their own. A culture of acceptance in the deliberative process means the inclusion of diverse and often conflicting opinions.

Based on the previous research on deliberative theories, a fair deliberative process can form in a culture of open-mindedness and diversity [12]. A fair, procedural deliberative process encourages participants to keep an open mind, and ensures diversity in the deliberative process. When people with diverse opinions co-mingle in the deliberative process, they freely express their opinions after deliberation [12]. When participants can freely accept or reject conflicting arguments, they can freely comment on a controversy [44]. Furthermore, securing the procedural fairness of the deliberative process and respecting the opinions of participants engaged in public debate increases the legitimacy of policy decisions after deliberation [16]. Thus, accepting diverse opinions in the deliberative process ensures a fair deliberative procedure [12]. 
Hypothesis 3. The culture of acceptance is positively associated with the perceived procedural fairness in the deliberative process.

\section{Methods}

\subsection{Contextual Backgrounds of Our Research}

In the past, deliberative democracy was practiced exclusively in Western countries, and did not develop in authoritarian countries. It would not be easy to attain procedural fairness in the decision-making process in non-Western countries that are not familiar with civic participation and democratic deliberation. In particular, public deliberation has not developed in countries with a Confucian tradition [45], including South Korea. With its authoritarian culture, South Korea did not recognize civic participation through public deliberation in policy decision-making for a long time. In South Korea, when democratization and diversity paved the way for economic growth through rapid industrialization in the 1990 s, conflicts among various members of society became serious. Since the 2000s, to overcome extreme conflicts of interest and conflict among members, the Korean government has actively introduced the public deliberation process as a transparent and fair participatory decision-making system that can enhance trust in the government. As citizens' desire and capacity to participate in the policy process increased, the government accommodated their active participation in the policy process to resolve conflicts.

The resumption of construction of the Shin-Gori Nuclear Reactors No. 5 and 6 in 2017 is a representative case of public deliberation (This part was constructed based on official reports by the Public Deliberation Committee on Shin-Gori Nuclear Reactors No. 5 and 6). The current President Moon, as a presidential candidate in 2017, pledged to halt the construction of the Shin-Gori Nuclear Reactors No. 5 and 6, according to post-nuclear policy. Nevertheless, as of May 2017, 28.8\% of the Shin-Gori nuclear reactors No. 5 and 6 had been constructed, and stopping the construction would have had a significantly negative effect on the local economy. Accordingly, on June 19 2017, President Moon declared that the matter regarding the suspension of the construction of the Shin-Gori Nuclear Reactors No. 5 and 6 would be decided through public deliberation by citizens. Moreover, he promised to follow the public's decision. Therefore, in July 2017, public deliberation on the suspension of construction of the Shin-Gori Nuclear Reactors No. 5 and 6 started, and lasted about three months.

\subsection{Sample and Data Collection}

Data for this study came from the '2017 Public Deliberation on Shin-Gori Nuclear Reactors No. 5 \& 6,' which made efforts to secure representativeness of sampling. Participants were recruited using a random telephone survey carried out between August 25 and September 9 2017. Out of all the adult men and women over 19 years old nationwide, 20,006 people were randomly selected according to the proportional sampling method stratified by region, gender, and age. The random telephone survey of 20,006 people completed the baseline survey and participants were asked if they would take part in a follow-up study on the energy issue. Of the 20,006 respondents, 5047 agreed to participate in a follow-up study, and 500 were selected from the 5047 using a proportional stratified sampling method between September 11 and 13. Finally, in the deliberative polling survey, 471 people participated for three days and two nights between October 13 and 152017.

Of the 471 participants, $238(50.5 \%)$ were female and $233(49.5 \%)$ were male. The age composition was as follows: $19-29$ years $(14.4 \%), 30-39$ years $(17 \%), 40-49$ years $(22.9 \%)$, $50-59$ years $(22.1 \%)$, and over 60 years $(23.6 \%)$. That is, participants had an average age of 47.17 years $(\mathrm{SD}=14.3)$ at the time of the questionnaire. Participants fell into eight job categories: agriculture/forestry/fishing (2.7\%), self-employment $(15.1 \%)$, sales/service jobs ( $7.9 \%)$, production/function/labor (5.1\%), office/management/professional $(30.6 \%)$, housewife (19.4\%), student $(8.7 \%)$, and others (10.8\%). In terms of education, $34(7.3 \%)$ completed middle school, 111 (23.8\%) graduated from high school, and 321 (68.8\%) completed university attendance or higher education. Finally, household income per month was 
classified into less than USD 1000 (4.7\%), USD 1000-2000 (8.3\%), USD 2000-3000 (18.6\%), USD 3000-4000 (13.1\%), USD 4000-5000 (16.3\%), USD 5000-6000 (16.5\%), USD 6000-7000 $(6.4 \%)$, and above USD 7000 (16.1\%).

The quasi-experiment involved structured and moderated face-to-face deliberations on the suspension of the construction of the Shin-Gori Nuclear Reactors No. 5 and 6. The first survey (T1) was conducted before the start of deliberations (October 13), and the second survey (T2) was conducted after deliberations ended (October 15). An intensive discussion was held from October 13 to 15 to help civic participants make decisions regarding suspending or resuming construction of the Shin-Gori Nuclear Reactors No. 5 and 6. More specifically, deliberative sessions were conducted in a focus-group laboratory for civic participatory members. Deliberative forums consisted of a small group discussion (9-10 members) and a presentation by experts on nuclear energy and the reasons for suspending or resuming construction of the Shin-Gori Nuclear Reactors No. 5 and 6. In addition, each small group discussion was designed to provide participants with information on both the pros and cons of each issue by experts. Furthermore, several small groups were led by different and independent moderators with experience in deliberative discussion.

In particular, the major topic of intensive discussion was related to the safety / environmental friendliness and the electricity supply/economic effect of the Shin-Gori Nuclear Reactors No. 5 and 6. The discussion took place in the order of a presentation by experts, group discussion, and the question-and-answer time with experts. First, experts made presentations on the pros and cons relating to the safety/environmental friendliness and electricity supply/economic effect of the Shin-Gori Nuclear Reactors No. 5 and 6. Second, each small group discussion was conducted to help participants learn about and understand each other in depth by sharing their thoughts and opinions on issues (safety/environmental friendliness and electricity supply/economic effect). Finally, after group discussion, civic participants conducted question-and-answer time with experts to better understand the issues.

\subsection{Measures}

To test our research ideas empirically, we administered the pre- and post-test to measure opinions on suspension or resumption of the construction of Shin-Gori Nuclear Reactors No. 5 and 6. The following sections describe the specific variables and related items that were included in the study.

\subsubsection{Dependent Variable}

Policy opinion change was a binary variable created by assigning a value of 1 to participants who changed their opinions (otherwise $=0$ ) regarding the suspension or resumption of the construction of Shin-Gori Nuclear Reactors No. 5 and 6 (policy opinion change means the change of views on the suspension or resumption of construction of the Shin-Gori Nuclear Reactors No. 5 and 6 (e.g., from no opinion to having an opinion, from having an opinion to no opinion, from halting to restarting an opinion, or from restarting to halting an opinion, and so on)). We measured the views on the suspension or resumption of the construction of Shin-Gori Nuclear Reactors No. 5 and 6 ( 1 = against resumption, 2 = for resumption, 3 = reserved judgment) at the pre- and post-test. The mean change in policy opinion was $0.24(\mathrm{SD}=0.43)$.

\subsubsection{Independent Variable}

Perceived fairness of the deliberative process assessed the perceived fairness of the deliberative procedure based on the previous research on deliberative procedural fairness $[12,15,23]$. At the post-test, participants evaluated the extent to which the deliberative procedure was perceived as fair on a 7-point scale (from 1 point to 7 points, denoting stronger agreement). We measured perceived procedural fairness using five items assessing the perceived fairness of the public deliberative process, including a deliberation sourcebook, video ma- 
terials, operators, moderators of small group discussion, and general deliberative process. The internal consistency estimate was 0.789 , with a mean of $5.65(\mathrm{SD}=0.79)$.

\subsubsection{Antecedent Variable}

Information reliability, as one of the antecedent variables, was measured based on the research of Luskin, et al. [10] on the quality of deliberation. At the post-test, we extracted eight items assessing the extent to which participants trust in information provided by the government, nuclear experts, nuclear power plants, civic groups, mass media, the internet, and expert opinions on pros and cons on a 7-point scale ranging from 1 point to 7 points, with higher scores indicating stronger agreement. The reliability of 8 items was 0.628 , and the mean of information reliability was $4.61(\mathrm{SD}=0.753)$.

Culture of acceptance, as another antecedent variable, was measured using three items (alpha reliability= 0.77) from Siu and Stanisevski [43] and Barabas [12]. At the post-test, we measured culture of acceptance in the deliberative process while considering the respect for diverse opinions of others, agreement with people who have different opinions, and the willingness to compromise one's opinion to achieve consensus on a 7-point scale (from 1 point to 7 points, denoting stronger agreement). The items were as follows: I respect others' views, even if they differ from mine; I can find consensus with someone who has different ideas; I can compromise my opinions to agree with someone with a different idea. The mean culture of acceptance was 5.67.

\subsubsection{Control Variable}

Control variables included participants' characteristics. More specifically, we asked the participants about their political orientation on a 5-point scale $(1=$ very progressive, $2=$ progressive, $3=$ medium, $4=$ conservative, $5=$ very conservative). The mean political orientation was $2.72(\mathrm{SD}=0.81)$. Social class status was measured using the following question: If Korean society were hypothetically divided into ten classes, which class do you think your family belongs to? (social class status increases from 1 to 10). The mean of social class status was $5.44(\mathrm{SD}=1.78)$. Moreover, we considered demographic variables, such as age, gender, educational level, household income, and job categories. Age was measured as actual age, and the other variables were measured as categorical variables.

\subsection{Statistical Techniques}

We used two statistical techniques to estimate our research topics empirically. First, we conducted quasi-experimental research to measure participants' change in opinion from the pre-test to the post-test as a dependent variable. Thus, we used logistic regression as our dependent variable (change in opinions) was dichotomous (binary). That is, we tested the effects of the perceived fairness of the deliberative process on change in opinions on the first model. Second, we used the ordinary least squares (OLS) regression model to estimate the effects of information reliability and culture of acceptance on the perceived fairness of the deliberative process on the second model.

To eliminate any common method bias, we tested the common method bias among the perceived fairness of the deliberative process, information reliability, and acceptance culture based on the study of Podsakoff, et al. [46]. The data indicated no common method bias. More specifically, we used some statistical remedies. First, partial correlation procedures indicated that correlations between the perceived fairness of the deliberative process, information reliability, and acceptance culture were below 0.9. Second, we conducted Harman's one-factor test, which is widely used to test common method bias [46]. In the relationships of perceived fairness of the deliberative process, information reliability, and acceptance culture, the largest factor accounted for $21.4 \%$ of the total variance. 


\section{Results}

\subsection{Participants' Change in Opinion}

Before testing the hypothesis, we assessed participants' opinions on Shin-Gori Nuclear Reactors No. 5 and 6 . At the pretest (T1), the results indicated that $44.7 \%$ of 471 participants wanted to resume construction, $30.7 \%$ wanted to halt construction, and $24.6 \%$ wanted to reserve their judgments. After the deliberative forum, at the post-test (T2), $57.2 \%$ of participants agreed to resume construction, $39.4 \%$ opposed the construction's resumption, and 3.3\% reserved their judgment (at the post-test, only two participants responded that they were not sure.) Thus, $24 \%$ of the participants changed their opinions $(\mathrm{SD}=0.43)$. The changes in opinions after the deliberation process are shown in Table 1.

Table 1. Participants Distribution of Pre-test and Post-test.

\begin{tabular}{ccccccc}
\hline & & \multicolumn{5}{c}{ Post-test (T2) } \\
\cline { 3 - 7 } & \multicolumn{1}{c}{$\begin{array}{c}\text { construction } \\
\text { halt }\end{array}$} & $\begin{array}{c}\text { construction } \\
\text { resumption }\end{array}$ & $\begin{array}{c}\text { reserved } \\
\text { judgment }\end{array}$ & $\begin{array}{c}\text { do not } \\
\text { know }\end{array}$ & Total \\
\hline $\begin{array}{c}\text { Pre-test } \\
(\mathrm{T} 1)\end{array}$ & $\begin{array}{c}\text { construction } \\
\text { halt }\end{array}$ & 147 & 3 & 1 & 2 & 153 \\
\cline { 2 - 7 } & $\begin{array}{c}\text { construction } \\
\text { resumption }\end{array}$ & 8 & 198 & 3 & 0 & 209 \\
\cline { 2 - 7 } & $\begin{array}{c}\text { reserved } \\
\text { judgment }\end{array}$ & 36 & 64 & 9 & 0 & 109 \\
\cline { 2 - 7 } & Total & 191 & 265 & 13 & 2 & 471 \\
\hline
\end{tabular}

As a result, most participants who changed their opinions did not make decisions at the pre-test. Out of the 109 participants who reserved their opinions at the pre-test, 36 participants voted for the construction halt of Shin-Gori Nuclear Reactors No. 5 and 6, and 64 participants voted for the construction's resumption at the post-test. Like previous research on the quality of deliberation [12], our results indicated that the participants with reserved opinions made clear decisions after the deliberative process. An intensive small group discussion for three days and two nights provided participants with learning opportunities about Shin-Gori Nuclear Reactors No. 5 and 6.

\subsection{Test for Hypothesized Models}

We used two-step models to test all hypotheses. Hypothesis 1 was tested using logistic regression. We tested whether the change in policy opinion arose solely from the perceived fairness of the deliberative process by including the perceived fairness of the deliberative process and participants' characteristics, as shown in Table 2. We found that the perceived fairness of the deliberative process was positively associated with the change in policy opinion. Participants shifted their opinions following deliberation when they perceived that the deliberative procedure was fair. This result was related to the fact that most participants perceived a high level of procedural fairness in the public deliberation (mean $=5.65)$. Consistent with the research on deliberative democracy, participants were more willing to accommodate others' opinions without prejudice and change their opinions when a fair public debate process was carried out [32].

Meanwhile, none of the personal variables significantly influenced policy opinion change, except for political orientation and job categories. This result was inconsistent with the research reporting a significant relationship of participants' age, education, and gender with their opinion shifts [47]. Nevertheless, participants' political orientation was significantly associated with their opinion change in this study. Participants with progressive political orientation were more likely to change their opinions after deliberation. These results highlight the importance of fairness rather than personal characteristics in the public deliberation process to achieve an effective outcome (opinion change). 
Table 2. Logistic Regression Models Predicting OpinionChange.

\begin{tabular}{|c|c|c|}
\hline Variables & Odds Ratio & Z Value (SE) \\
\hline $\begin{array}{l}\text { Perceived Fairness of } \\
\text { Deliberative Process }\end{array}$ & 1.42 & $2.40 * *(0.206)$ \\
\hline Social Class Status & 0.923 & $-0.99(0.074)$ \\
\hline Political Orientation & 0.770 & $-\mathbf{1 . 8 6} *(0.107)$ \\
\hline Job Categories & 1.127 & $2.01 * *(0.066)$ \\
\hline Household Income & 1.009 & $0.13(0.071)$ \\
\hline Age & 0.992 & $-0.97(0.007)$ \\
\hline Gender & 0.935 & $-0.30(0.207)$ \\
\hline Educational Level & 0.969 & $-0.16(0.187)$ \\
\hline LR $x^{2}$ & \multicolumn{2}{|c|}{$19.25 * *$} \\
\hline -2 Log-likelihood & \multicolumn{2}{|c|}{501.2} \\
\hline
\end{tabular}

Notes: Standard errors are shown in brackets on the diagonal. ${ }^{*} p<0.1$ (two-tailed test). ${ }^{* *} p<0.05$ (two-tailed test).

Next, we tested Hypotheses 2 and 3 using OLS to examine the relationships between perceived fairness of the deliberative process, information reliability, and acceptance culture. Table 3 shows the positive influence of information reliability and acceptance of perceived fairness of the deliberative process when controlling for participants' characteristics. Thus, Hypothesis 2 and 3 were supported. These results were consistent with the argument that a fair deliberative process forms when the information provided to participants is reliable and participants are willing to accept opinions that are different from theirs [12]. Accordingly, to cultivate procedural fairness in the deliberation process, information reliability and a culture of acceptance need to be secured. However, only the participants' political orientation was significantly associated with the deliberative process' perceived fairness. That is, participants with a more progressive political orientation were more likely to perceive their deliberative process to be fair.

Table 3. Results of Regression Analysis with the Emergence of Perceived Fairness of Deliberative Process.

\begin{tabular}{cc}
\hline Variables & Perceived Fairness of Deliberative Process \\
\hline Information Reliability & $\mathbf{0 . 2 1 4}{ }^{* *}(0.050)$ \\
\hline Culture of Acceptance & $\mathbf{0 . 1 3 9 * *}(0.047)$ \\
\hline Social Class Status & $-0.014(0.026)$ \\
\hline Political Orientation & $\mathbf{- 0 . 0 8 4} *^{*}(0.046)$ \\
\hline Job Categories & $0.010(0.019)$ \\
\hline Household Income & $0.004(0.022)$ \\
\hline Age & $-0.0003(0.002)$ \\
\hline Gender & $0.117(0.073)$ \\
\hline Educational Level & $0.077(0.067)$ \\
\hline Cons & $3.75(0.44)$ \\
\hline $\mathrm{R}^{2}$ & $0.082 * * *$
\end{tabular}

Notes: Standard errors are shown in brackets on the diagonal. ${ }^{*} p<0.1$ (two-tailed test); ${ }^{* * *} p<0.01$ (two-tailed test). 


\section{Conclusions}

\subsection{Implications for Sustainable Deliberative Democracy}

Our results suggest that the perceived procedural fairness of the deliberative process is a key factor in altering participants' opinions. These results support Gutmann and Thompson's [7] argument that participants can agree on the outcome of deliberation when they have access to the opinions and reasoning of all members, because a fair deliberative procedure can be formed based on reasons and inclusion. Hence, an outcome of deliberation can be achieved when participants trust that the deliberation process is fair.

Accordingly, how can we cultivate the perceived fairness of the deliberative process? We found that providing more reliable information to participants and fostering a culture of higher acceptance among them increased the perceived fairness of deliberative procedures. Therefore, when participants trust the information provided by the government and experts in the deliberative process, they are likely to believe that the deliberative democracy is fair because the increase in reliable information helps participants make rational judgments in the deliberative process. As such, reliable information must be included in deliberation for a successful outcome [39]. However, although participants in our research scored aboveaverage on information reliability (mean $=4.61$ ), they still did not show full confidence in the information provided by the government, experts, civic groups, and other individuals. This might be because Koreans have little experience in public deliberation due to Korea's brief history of deliberative democracy. Thus, officials who facilitate policy deliberation need to provide participants with accurate and reliable information on the issue under deliberation.

In the same vein, we found that participants perceived the deliberative process to be fair in a culture where various opinions are accommodated, and compromised their opinions to achieve consensus. Our research is particularly meaningful because it emphasizes the importance of the culture of acceptance and tolerance in the perception of fairness of the deliberative process, even in a Confucian country that has maintained an authoritarian culture for a long time [45]. This result is consistent with the argument that mutual trust and understanding are required for constructive deliberation. In particular, participants must keep an open and trusting mind to avoid the risks of enclave deliberation in a deeply divided society [1]. Citizens should be educated about deliberative discussion, conventions, and norms. Despite the importance of trust and mutual respect, it takes a long time for citizens to accomplish these ideals in public deliberation. Therefore, in countries that have maintained an authoritarian culture for a long time, citizens need to respect mutual opinions.

\subsection{Limitation and Future Research}

Despite these meaningful findings, our research has some limitations. First, although we analyzed the effects and antecedents of the perceived fairness in the deliberation using the quasi-experiment method, we did not compare the deliberative group (experiment group) with control groups. We measured the participants' opinion change from pre- to post-test, but we did not include control groups. Thus, a future study needs to incorporate control groups to assess the validity and reliability of the research. Furthermore, for a valid measurement of participants' opinion changes, we should conduct qualitative research utilizing in-depth interviews.

Second, the Shin-Gori Nuclear Reactors No. 5 and 6 were our target of deliberation. Deliberative theories state that outcome of public deliberation depends on the characteristics of the participants. Most of all, the outcome of public deliberation depends on the extent to which deliberative participants are representatively selected [1,7]. Our study attempted to recruit participants representative of the general population based on the random stratified sampling reflecting the population's characteristics. Nevertheless, our findings may have limited generalizability to other public deliberation cases. Accordingly, future research should expand the target samples. For example, comparative studies of other nationwide and local deliberations will help generalize our research findings. 
Finally, we measured only two antecedents of the perceived fairness of the deliberative process, specifically information on reliability and the culture of acceptance. Future studies could incorporate other antecedent variables. For example, we need to examine the extent to which participants' psychological orientations and group composition affects the perceived fairness of the deliberative process [47]. Future studies need to consider various methods to cultivate the perceived fairness of the deliberative process for constructive deliberative democracy.

Funding: This work was supported by the University of Suwon, 2019.

Data Availability Statement: In this study, author used the secondary data which was collected by Korean government organization (Public Deliberation Committee on Shin-Gori Nuclear Reactors No. 5 \& 6).

Conflicts of Interest: The author declares no conflict of interest.

\section{References}

1. Fishkin, J.S. When the People Speak: Deliberative Democracy and Public Consultation; Oxford University Press: Oxford, UK, 2009.

2. Dryzek, J.S. Theory, evidence and the tasks of deliberation. In Can the People Govern? Deliberation, Participation and Democracy; Rosenberg, S.W., Ed.; Palgrave Macmillan: Houndmills, UK, 2007; pp. 237-250.

3. McKillop, C. Predicting the Outcome of Deliberative Democracy. In Proceedings of the 57th Annual Meeting of the Association for Computational Linguistics, Florence, Italy, 28 July-2 August 2019.

4. Niemeyer, S. The Emancipatory Effect of Deliberation: Empirical Lessons from Mini-Publics. Political Soc. 2011, 39, 103-140. [CrossRef]

5. Mutz, D.C. Is deliberative democracy a falsifiable theory? Annu. Rev. Political Sci. 2008, 11, 521-538. [CrossRef]

6. Habermas, J. The Structural Transformation of the Public Sphere; MIT Press: Cambridge, MA, USA, 1989.

7. Guttman, A.; Thompson, D. Democracy and Disagreement; Harvard University Press: Cambridge, MA, USA, 1996.

8. Sass, J.; Dryzek, J.S. Deliberative cultures. Political Theor. 2014, 42, 3-25. [CrossRef]

9. Carman, C. The Process is the Reality: Perceptions of Procedural Fairness and Participatory Democracy. Political Stud. 2010, 58, 731-751. [CrossRef]

10. Luskin, R.C.; Fishkin, J.S.; Jowell, R. Considered Opinions: Deliberative Polling in Britain. Br. J. Political Sci. 2002, 32, $455-487$. [CrossRef]

11. Steenbergen, M.; Bächtiger, A.; Spörndli, M.; Steiner, J. Measuring Political Deliberation: A Discourse Quality Index. Comp. Eur. Political 2003, 1, 21-48. [CrossRef]

12. Barabas, J. How Deliberation Affects Policy Opinions. Am. Political Sci. Rev. 2004, 98, 687-701. [CrossRef]

13. Carpini, M.X.D.; Cook, F.L.; Jacobs, L.R. Public Deliberation, Discursive Participation, and Citizen Engagement: A Review of the Empirical Literature. Am. Rev. Political Sci. 2004, 7, 315-344. [CrossRef]

14. Mendelberg, T.; Karpowitz, C.F. Deliberating about Justice. In Deliberation, Participation, and Democracy: Can the People Govern? Rosenberg, S., Ed.; Palgrave Macmillan: New York, NY, USA, 2007; pp. 101-129.

15. Zhang, W. Perceived procedural fairness in deliberation: Predictors and effects. Commun. Res. 2015, 42, 345-364. [CrossRef]

16. Cohen, J. Deliberation and Democratic Legitimacy. In The Good Policy; Hamlin, A., Pettit, P., Eds.; Basil Blackwell: Oxford, UK, 1989; pp. 17-34.

17. Janis, I.L. Groupthink: Psychological Studies of Policy Decisions and Fiascoes, 2nd ed.; Houghton Mifflin: New York, NY, USA, 1982.

18. Page, B. Who Deliberates? Mass Media in Modern Democracy; University of Chicago Press: Chicago, IL, USA, 1996.

19. Young, I.M. Communication and the Other: Beyond Deliberative Democracy. In Democracy and Difference; Benhabib, S., Ed.; Princeton University Press: Princeton, NJ, USA, 1996; pp. 120-135.

20. Burkhalter, S.; Gastil, J.; Kelshaw, T. A conceptual definition and theoretical model of public deliberation in small face-to-face groups. Commun. Theor. 2002, 12, 398-422.

21. Estlund, D. Beyond fairness of deliberation: The epistemic dimension of democratic authority. In Deliberative Democracy: Essays on Reason and Politics; Bohman, J., Rehg, W., Eds.; The MIT Press: London, UK, 1997; pp. 173-204.

22. Goodin, R.E. Democratic Deliberation Within. Philos. Public Aff. 2000, 29, 81-109. [CrossRef]

23. Herian, M.N.; Hamm, J.A.; Tomkins, A.J.; Zillig, L.M.P. Public participation, procedural fairness, and evaluations of local governance: The moderating role of uncertainty. J. Publ. Adm. Res. Theor. 2012, 22, 815-840. [CrossRef]

24. Denver, D.; Hands, G.; Jones, B. Fishkin and the Deliberative Opinion Poll: Lessons from a Study of the Granada 500 Television Program. Political Commun. 1995, 12, 147-158. [CrossRef]

25. Himmelroos, S.; Christensen, H.S. Deliberation and Opinion Change: Evidence from a Deliberative Mini-Public in Finland. Scand. Political Stud. 2014, 37, 41-60. [CrossRef]

26. Westwood, S.J. The Role of Persuasion in Deliberative Opinion Change. Political Commun. 2015, 32, 509-528. [CrossRef]

27. Bohman, J. Public Deliberation: Pluralism, Complexity and Democracy; MIT Press: Cambridge, MA, USA, 1998. 
28. Vinokur, V.; Burnstein, E. Depolarization of attitudes in groups. J. Pers. Soc. Psychol. 1978, 36, 872-885. [CrossRef]

29. Allport, G.W. The Nature of Prejudice; Addison-Wesley: Reading, MA, USA, 1954.

30. Gaertner, S.L.; Dovidio, J.F.; Rust, M.C. Reducing intergroup bias: Elements of intergroup cooperation. J. Pers. Soc. Psychol. 1999, 76, 388-402. [CrossRef]

31. Dovidio, J.F.; Love, A.; Schellhaas, F.M.H.; Hewstone, M. Reducing intergroup bias through intergroup contact: Twenty years of progress and future directions. Group Process. Intergroup 2017, 20, 606-620. [CrossRef]

32. Hughes, T.; Pollard, A. Changing Hats: How Deliberation Impacts Citizens; Sciencewise Expert Resource Centre: Cambridge, UK, 2014.

33. Tyler, T. Social Justice: Outcome and Procedure. Int. J. Psychol. 2000, 35, 117-125. [CrossRef]

34. Grimes, M. Organizing consent: The role of procedural fairness in political trust and compliance. Eur. J. Political Res. 2006, 45, 285-315. [CrossRef]

35. Meade, E.E.; Stasavage, D. Two Effects of Transparency on the Quality of Deliberation. Swiss Political Sci. Rev. 2005, 12, 123-133.

36. Thibaut, J.; Walker, L. A theory of procedure. Calif. Law Rev. 1978, 66, 541-566. [CrossRef]

37. Folger, R. Distributive and procedural justice: Combined impact of "voice" and improvement on experienced inequity. J. Pers. Soc. Psychol. 1977, 35, 108-119. [CrossRef]

38. Alvarez, R.M. Information and Elections; University of Michigan Press: Ann Arbor, MI, USA, 1997.

39. Indermaur, D.; Roberts, L.; Spiranovic, C.; Mackenzie, G.; Gelb, K. A matter of judgement: The effect of information and deliberation on public attitudes to punishment. Punishm. Soc. 2012, 14, 147-165. [CrossRef]

40. Hofstede, G. Culture's Consequences: Comparing Values, Behaviors, Institutions and Organizations across Nations; Sage: Thousand Oaks, CA, USA, 2001.

41. Colquitt, J.A.; Conlon, D.E.; Wesson, M.J.; Porter, C.O.L.H.; Ng, K.Y. Justice at the millennium: A meta-analytic review of 25 years of organizational justice research. J. Appl. Psychol. 2001, 86, 425-445. [CrossRef] [PubMed]

42. Blau, P. Exchange and Power in Social Life; Wiley: New York, NY, USA, 1964.

43. Siu, A.; Stanisevski, D. Deliberation in multicultural societies: Addressing inequality, exclusion, and marginalization. In Democracy in Motion: Evaluating the Practice and Impact of Deliberative Civic Engagement; Nabatchi, T., Gastil, J., Leighninger, M., Weiksner, G.M., Eds.; Oxford University Press: Oxford, UK, 2012; pp. 83-102.

44. Zaller, J. The Nature and Origins of Mass Opinion; Cambridge University Press: Cambridge, MA, USA, 1992.

45. He, B. Deliberative Culture and Politics: The Persistence of Authoritarian Deliberation in China. Political Theor. 2014, 42, 58-81. [CrossRef]

46. Podsakoff, P.M.; MacKenzie, S.B.; Lee, J.-Y.; Podsakoff, N.P. Common method biases in behavioral research. J. Appl. Physiol. 2003, 88, 879-903.

47. Suiter, J.; Farrell, D.M.; O'Malley, E. When do deliberative citizens change their opinions? Evidence from the Irish Citizens' Assembly. Int. Political Sci. Rev. 2014, 37, 198-212. [CrossRef] 